\title{
International Registration of Cultivar Names for Unassigned Woody Genera 1994
}

\author{
Steven E. Clemants ${ }^{1}$ \\ Brooklyn Botanic Garden, 1000 Washington Avenue, Brooklyn, NY 11225-1099, USA
}

Theodore R. Dudley, 57, died on 17 Nov. 1994 of a brain tumor. Dudley, a Research Botanist with the U.S. National Arboretum, had served as registrar for the International Registration Authority (IRA) for Cultivar Names of Unassigned Woody Genera from 1 Jan. 1981 to 31 May 1984, when the late D.G. Huttleston took over. Following the untimely death of "Dutch" Huttleston [see HortScience 29(9): 970971], "Ted" Dudley indicated his willingness to take on registration duties once more. Before he could do so, however, he was forced to retire by ill health.

Some applications for registration may have been lost as a result of changing addresses and forwarding of mail. Applicants whose registration(s) appeared neither in HortScience 29(9): 970-971 nor in this paper should contact the current registrar at the given address.

During 1994, eight cultivar names in unassigned woody genera were registered. Photos and herbarium specimens have been deposited in the Brooklyn Botanic Garden Herbarium. Anyone who is involved in originating or introducing new cultivars of ornamental plants is urged to assure that the names are registered with a view to nomenclatural stabilization. A list of the International Registration Authorities is available from the American Association of Botanical Gardens and Arboreta, 786 Church Rd., Wayne, PA 19087, USA.

Arctostaphylos uva-ursi (L.) Sprengel 'Tom's Point'. Registered 7 Dec. 1994. Registrant: Bertram G. Johnson, Regional Parks Botanical Garden, Tilden Regional Park, Berkeley, CA 94708. The original plant was collected by James Roof, Regional Parks Botanical Garden, and was selected in 1992 by Johnson for its low, dense, and uniform habit; showy flowers; abundant fruit; and particularly for its glossy leaves. It shows no sign of dieback or disease and has been unfazed by several freezes. A valid description appeared in The Four Seasons: Journal of the Regional Parks Botanical Garden [9(3): 42-43, 1993].

Baccharis pilularis DeCandolle 'Al's Blue'. Registered 7 Dec. 1994. Registrant: Al Seneres, Regional Parks Botanic Garden, Tilden Regional Park, Berkeley, CA 94708. Seneres selected cuttings from the wild in 1984. The cultivar has a dense mounding and uniform habit, blue on light green foliage, good weed suppression, and fast growth (with some summer watering, it grows 3 feet higher than the usual 1foot height of the species). In addition, it produces bisexual flowers. A valid description appeared in The Four Seasons: Journal of the Regional Parks Botanical Garden [9(2): 43, 1992].

Catalpa Xerubescens Carr. 'Victoria'. Registered 18 Oct. 1994. Registrant: Steven Alex Zalany, 29045 Detroit Rd., Westlake, OH 44145. In 1992, Zelany found this plant growing at Queen Victoria Park, Niagara Falls, Ontario, Canada. It is a double-flowered, sterile form of Catalpa xerubescens and produces no fruit. It differs from Catalpa Xerubescens 'Adina' because it is sterile and has no stamens in the flower. It is hardy in U.S. Dept. of Agriculture hardiness zone 4.

${ }^{1}$ Taxonomist, Brooklyn Botanic Garden, and registrar for unassigned woody genera.
Cuphea 'Starfire'. Registered 18 Oct. 1994. Registrant: W.W. Roath, U.S. Dept. of Agriculture-Agricultural Research Service, North Central Regional Plant Introduction Station, Iowa State Univ., Ames, IA 50011. This is an artificial and sterile hybrid between $C$. ignea and C. angustifolia, selected by A.E. Thompson in 1990 for its dark green foliage, pink floral tube, and bicolored petals. It is hardy to U.S. Dept. of Agriculture hardiness zone 10 and is proposed for use as a potted plant in the greenhouse or house under moderately high light intensities. A valid description appears in HortScience [30(1):166-167. 1995].

Fraxinus americana L. 'Junginger'. Registered 18 Oct. 1994. Registrant: Bernard Fourrier, McKay Nursery Co., 254 Jefferson St., P.O. Box 185, Waterloo, WI 53594. G. William Longenecker, Univ. of Wisconsin-Madison, selected this plant from a chance seedling in 1955, it was introduced in 1956 by McKay Nursery. This cultivar is named for Karl Junginger of the McKay Nursery (1905-1991). It was selected for its leathery, deep-green, glossy foliage that has beautiful and prolonged fall colors, varying from mottled yellow-orange to deep purple or mahogany, depending on the year with golden leaves in the interior of the crown. This tree is seedless with a rounded shape (50 feet $\times 50$ feet) and light-grey bark. Hardy in U.S. Dept. of Agriculture hardiness zones 3 to 9. McKay Nurseries has registered a trademark under the name Autumn Purple for this plant.

Halesia tetraptera Ellis 'Silver Splash'. Registered 7 Dec. 1994. Registrant: James E. Janczewski, Tyler Arboretum, 515 Painter Rd., Media, PA 19063. Members of the Tyler Arboretum staff selected this plant from a sport in 1992. The leaves are green, randomly interspersed with a silver-white and yellow variegation. It is hardy in Arnold Arboretum hardiness zones 4 to 8 .

Prunus virginiana L. 'Robert'. Registered 9 Dec. 1994. Registrant: Lloyd E. Lee, Site 16, Box 9, RR 2, Barrhead, AB, Canada T7N 1N3. This cultivar was named for Robert Simonet. Lloyd Lee selected this shrub in 1984. The original seed of one of the parents was given to him by Robert Simonet. This shrub is large (14 feet tall) with red-purple leaves ('Shubert'-like) and compact fruit clusters of large berries that have a mild taste. It is hardy in zone 2 and is adaptable to a wide range of soils and locations. A valid description and photo can be found in Gardening in Alberta [11(5):16-17, June 1993].

Vaccinium ovatum Pursh 'Twinkle'. Registered 9 Dec. 1994. Registrant: Pat Halligan, 5536 Harbor, P.O. Box 489, Freeland WA 98249. This cultivar was named for Pat Halligan's daughter whose nickname is Twinkle. In 1990, Pat Halligan selected a single branch of a $V$. ovatum individual in Pacific Co., Washington, USA, for its miniature form (all parts: leaves, branches, flowers, and fruit are half normal size). It has a dense, dwarf habit; miniature leaves and flowers; dark-green shiny leaves; bronze new growth; and small pink flowers. It should be hardy within the range of $V$. ovatum. 